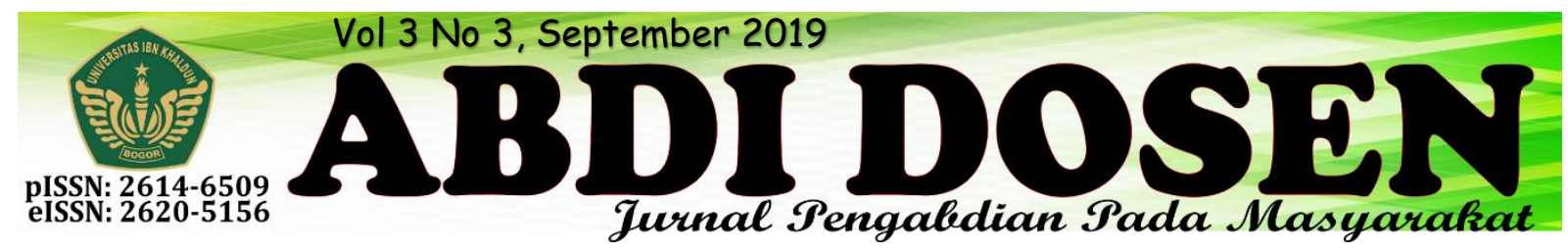

\title{
MENGEMBANGKAN POTENSI MASYARAKAT MELALUI PENDIDIKAN NON FORMAL UNTUK MENINGKATKAN SDM, SERTA PEMBERDAYAAN DI KP.GUNUNG LEUTIK, RW 05 DESA BENTENG
}

\author{
Hidayah Baisa $^{1}$, Kiki Agustianto ${ }^{2}$ \\ hidbaisa@ fai.uika-bogor.ac.id ${ }^{1}$ \\ kikiagus18@gmail.com ${ }^{2}$ \\ Fakultas Agama Islam Universitas Ibn Khaldun ${ }^{1}$, Mahasiswa KKN Kelompok 08 Tahun $2018^{2}$
}

\begin{abstract}
ABSTRAK
Universitas Ibn Khaldun Bogor merupakan salah satu Universitas yang mengadakan Kuliah Kerja Nyata, bagian integral dalam proses pendidikan yang merupakan usaha sadar untuk menyiapkan mahasiswa melalui kegiatan bimbingan, pengajaran dan atau latihan agar mau dan dapat melaksanakan perannya dimasa yang akan datang, sesuai dengan yang diharapkan. Dengan demikian KKN merupakan proses pendidikan untuk mengamalkan ilmu pengetahuan, teknologi dan seni secara melembaga langsung kepada masyarakat dengan tujuan utama membentuk sarjana-sarjana siap dan berguna serta membantu proses pembangunan sosial. Kuliah Kerja Nyata Universitas Ibn Khaldun Bogor Tahun 2018 periode 07 Agustus -5 september 2018 yang berlokasi di Kp. Gunung Leutik merupakan salah satu kampung yang berada di dusun 2, desa benteng,kecamatan ciampea, kabupaten bogor. Program kerja kelompok terdiri dari program fisik, non-fisik, tambahan, dan kegiatan insidental. Sedangkan program kerja individu terdiri dari program kerja individu utama, dan program kerja individu penunjang. Program kerja kelompok fisik meliputi.Pembuatan Jembatan bambu untuk mempermudah akses kekali cihideung dan dekorasi paud syamil. Sedangkan progam non fisik adalah pengajaran di sd,paud,smp,dan bimbel, serta penyuluhan dan pelatihan kepada warga dan pembuatan website kampung wisata. Pada pelaksanaannya, program kerja kelompok KKN 8 berjalan dengan baik, meskipun tak jarang ada beberapa kendala yang terjadi. Namun, dengan kerja sama yang baik antara mahasiswa KKN dan masyarakat setempat, hambatan tersebut dapat teratasi. Dukungan dari berbagai pihak khususnya masyarakat kp.gunung leutik dan universitas sangat membantu dalam kelancaran pelaksanaan program kerja kelompok KKN 8.
\end{abstract}

Kata Kunci: KKN,Program Kerja,Desa Benteng

\section{PENDAHULUAN}

\section{Latar Belakang}

Kuliah Kerja Nyata (yang selanjutnya disebut $\mathrm{KKN}$ ) adalah suatu kegitan yang termasuk dalam satu Tri Dharma Pengguruan Tinggi yang Ketiga, yaitu: pengabdian kepada masyarakat, dimana kegiatan ini dilaksanakan oleh mahasiswa yang mencakup segala tugas dan teori-teori yang didapat dibangku kuliah yang diwujudkan kedalam kegiatan 
langsung mahasiswa pada suatu masyarakat atau lembaga, sehingga menjadi pengalaman yang dapat meningkatkan kedewasaan dan profesionalitas mahasiswa untuk memperbaharui dan mewujudkan tatanan kehidupan masyarakat yang lebih baik.

Pendidikan dalam arti luas berarti suatu proses untuk mengembangkan semua aspek kepribadian manusia, yang mencakup pengetauannya, nilai serta sikapnya dan ketrampilannya. (Achmad Munib, 2004)

Pendidikan nonformal dengan berbagai atribut dan nama atau istilah lainnya, baik disebut dengan, mass education, adult education, lifelong education, learning society,out-of-school education, social education dll, merupakan kegiatan yang terorganisir dan sistematis yang diselenggarakan di luar subsistem pendidikan formal. (Sudjana, 1994). Meskipun kesemua istilah tersebut memiliki perbedaan dan kesamaan dengan pendidikan nonformal, akan tetapi sangat sulit untuk merumuskan pengertian yang konprehensif dan berlaku umum, mengingat titik pandang yang berbeda.

Sasaran pendidikan nonformal dapat ditinjau dari beberapa segi, yakni pelayanan, sasaran khusus, pranata sistem pengajaran dan pelembagaan program. Ditilik dari segi pelayanan, sasaran pendidikan nonformal adalah melayani anak usia sekolah (0-6 tahun), anak usia sekolah dasar (7-12 tahun), anak usia pendidikan menengah (13-18 tahun), anak usia perguruan tinggi (19-24 tahun). Ditinjau dari segi sasaran khusus, pendidikan nonformal mendidik anak terlantar, anak yatim piatu, korban narkoba, perempuan penghibur, anak cacat mentau maupun cacat tubuh. Dari segi pranata, penyelenggaraan kegiatan pembelajaran dilakukan dilingkungan keluarga, pendidikan perluasan wawasan desa dan pendidikan keterampilan. Di segi layanan masyarakat, sasaran pendidikan nonformal antara lain membantu masyarakat melalui program $\mathrm{PKK}, \mathrm{KB}$, perawatan bayi, peningkatan gizi keluarga, pengetahuan rumah tangga dan penjagaan lingkungan sehat. Dilihat dari segi pengajaran, sasaran pendidikan nonformalsebagai penyelenggara dan pelaksana program kelompok, organisasi dan lembaga pendidikan, program kesenian tradisional ataupun kesenian modern lainnya yaitu menjadi fasilitator bahkan turut serta dalam program keagamaan, seperti mengisi pengajaran di majelis taklim, di pondok pesantren, dan bahkan di beberapa tempat kursus. Sedangkan sasaran pendidikan nonformal ditinjau dari segi pelembagaan, yakni kemitraan atau bermitra dengan berbagai pihak penyelenggara program pemberdayaan masyarakat berkoordinasi dengan desa atau pelaksana program pembangunan.

Bagaimana dengan karakteristik pendidikan nonformal? Secara khusus pendidikan nonformal memiliki spesifikasi yang 'unik' dibanding pendidikan sekolah, terutama dari berbagai aspek yang dicakupinya. Ini terlihat dari tujuan pendidikan nonformal, yakni memenuhi kebutuhan belajar tertentu yang fungsional bagi kehidupan masa kini dan masa depan, dimana dalam pelaksanananya tidak terlalu menekankan pada ijazah. Dalam waktu pelaksanannya, pendidikan nonformal terbilang relatif singkat, menekankan pada kebutuhan di masa sekarang dan masa yang akan datang serta tidak penuh dalam menggunakan waktu alias tidak terus menerus.

Isi dari program pendidikan nonformal ini berpedolam pada kurikulum 
pusat pada kepentingan peserta didik (warga belajar), mengutamakan aplikasi dimana menekanannya terletak pada keterampilan yang bernilai guna bagi kehidupan peserta didik dan lingkungannya. Soal persyaratan masuk pendidikan nonformal, hal itu ditetapkan berdasarkan hasil kesepakatan bersama antara sesama peserta didik. Proses belajar mengajar dalam pendidikan nonformal pun relative lebih fleksibel, artinya diselenggarakan di lingkungan masyarakat dan keluarga.

Lingkungan yang berfungsi melahirkan individu - individu terdidik (educationa lindividuals) bukan hanya lingkungan keluarga yang disebut juga lingkungan pertama, lingkungan sekolah yang disebut juga lingkungan kedua, tetapi juga lingkungan masyarakat yangdisebut juga lingkungan ketiga (Purwanto, 1986). Peranan penting pendidikan pada lingkungan ketiga yang dikenal dengan lingkungan masyarakat atau pendidikan non formal dikarenakan manusia adalah makhluk sosial. Sebagai makhluk social manusia menjadi bagian dari pelbagai golongan dalam masyarakat, baik dengan sendirinya maupun dengan sengaja. Manusia dengan sendirinya adalah bagian dari keluarga, kota, negara dan kelompok agama. Tapi ada juga golongan yang dengan sengaja dimasuki seperti perkumpulan olah raga, serikat pekerja, koperasi, organisasi politik, perkumpulan kesenian dan lain-lain. Melalui kelompok kelompok inilah pendidikan nonformal dilakukan. Pendidikan nonformal dapat menjadi pelengkap dari pendidikan formal, terlebih jika dikaitkan dengan keterbatasan - keterbatasan yang diakibatkan karena adanya krisis.

Cikal bakal kegiatan mahasiswa terjun ke lapangan telah ada sejak dahulu, kemudian kegiatan mahasiswa lebih ditingkatkan lagi setelah pada bulan Februari 1972 dengan adanya anjuran dan dorongan agar mahasiswa lebih berupaya membangun desa dengan cara belajar dan bekerja dalam waktu tertentu, tinggal dan membentuk masyarakat pedesaan, memecahkan persoalan pembangunan pendesaan agar menjadi lebih maju.

Universitas Ibn Khaldun Bogor merupakan salah satu Universitas yang mengadakan Kuliah Kerja Nyata, bagian integral dalam proses pendidikan yang merupakan usaha sadar untuk menyiapkan mahasiswa melalui kegiatan bimbingan, pengajaran dan atau latihan agar mau dan dapat melaksanakan perannya dimasa yang akan datang, sesuai dengan yang diharapkan. Dengan demikian KKN merupakan proses pendidikan untuk mengamalkan ilmu pengetahuan, teknologi dan seni secara melembaga langsung kepada masyarakat dengan tujuan utama membentuk sarjana-sarjana siap dan berguna serta membantu proses pembangunan sosial.

Pembekalan KKN diselenggarakan oleh Bupati Bogor Dan pihak LPPM pada tanggal 7 Agustus 2018 di Masjid Raya Al - Hijr 2 dan membekali mahasiswa dengan materi pemberdayaan masyarakat melalui KKN, materi tentang POSDAYA, serta materi yang terkait dengan teknis kegiatan KKN. Melakukan koordinasi dengan Dosen Pembimbing Lapangan (DPL) KKN kelompok secara efektif. Mahasiswa KKN juga mengadakan pertemuan secara rutin membahas program kerja. Ketika penerjunan ke lokasi KKN, para mahasiswa melakukan kegiatan observasi. Kegiatan ini dilakukan sebelum mahasiswa benar-benar terjun ke lokasi KKN. Kegiatan ini dilakukan untuk mengamati secara langsung terhadap situasi, kondisi, 
sarana, dan pasarana yang ada di lokasi KKN dalam hal ini Desa guna mendukung proses kuliah kerja nyata di Desa Benteng tersebut.

\section{Kondisi Wilayah}

Kp. Gunung Leutik merupakan salah satu kampung yang berada di dusun 2, desa benteng,kecamatan ciampea, kabupaten bogor.Benteng merupakan salah satu dari Desa di Wilayah Kecamatan Ciampea Kabupaten Bogor.

\begin{tabular}{|c|l|c|}
\hline No & Keterangan & Berbatasan \\
\hline 1 & Utara & Desa Rancabungur \\
\hline 2 & Selatan & $\begin{array}{c}\text { Desa Bojong Rangkas } \\
\text { dan Desa Cibanteng }\end{array}$ \\
\hline 3 & Barat & Desa Ciampea \\
\hline 4 & Timur & Desa Dramaga \\
\hline 5 & Luas Daerah & 313 Ha \\
\hline 6 & $\begin{array}{l}\text { Jumlah } \\
\text { Penduduk }\end{array}$ & 6.833 Jiwa \\
\hline
\end{tabular}

\section{Keadaan topografi desa}

Secara geografis Desa Benteng Kecamatan Ciampea Kabupaten Bogor ini berada di daerah Agraris Pertanian dengan suhu rata-rata harian adalah $30-40{ }^{\circ} \mathrm{C}$ iklim Desa Benteng sebagaimana desa-desa lain di wilayah Indonesia dalam wilayah Tropis mempunyai iklim Kemarau dan Penghujan, hal tersebut mempunyai pengaruh langsung terhadap pola tanam yang ada di Desa Benteng Kecamatan Ciampea iklim suatu daerah sangat berpengaruh dalam kehidupan utamanya untuk pertumbuhan tanaman dan kelangsungan hidup binatang ternak. Selain itu, kondisi geografis Desa Benteng umumnya merupakan daerah Agraris Pertanian.

\section{Bidang Ekonomi}

Seperti yang sudah dijelaskan diatas selain bidang pertanian masyarakat Gunung leutik, banyak yang menjalankan industri rumahan namun para pengusaha industri rumahan (dering, emping dan browncav (brownies mocav)) ini masih kesulitan dalam memasarkan produknya. Selain itu para ibu rumah tangga banyak yang tidak memiliki pekerjaan sehingga jika tidak ada pesanan maka mereka tidak mendapatkan pemasukan. Dan hal ini berdampak juga bagi anak-anak mereka dalam hal uang saku.Bukan Hanya Itu Masyarakat masih percaya dengan bank keliling bahkan ada yang menjadi Rentenir atau nasabah.

2. Bidang sosial dan masyarakat

Kurangnya kesadaran masyarakat akan pentingnya gotong royong sesama warganya dan belum terbentuknya karang taruna atau komunitas pemuda. Karena disebabkan mayoritas masyarakat sebagai pekerja dan petani akibatnya masyarakat menjadi kurang kesadaranya terhadap dalam bidang sosial.

3. Bidang Pendidikan

Kurangnya kesadaran masyarakat terhadap pendidikan, bahkan ada anggapan sekolah itu mahal dan jauh. Jangankan Buat bayar sekolah Juga susah apalagi buat sekolah Maka tak heran penduduk Kp.Gunung Leutik rata-rata pendidikannya SD \& SMP. 


\section{METODE PENGABDIAN}

Peningkatan potensi masyarakat melalui pendidikan non formal Di Kp.Gunung Leutik,Rw 05 Desa Benteng Kecamatan Ciampea Kabupaten
Bogor,Adapun pendekatan, metode, dan tahapan pelaksanaan kegiatan yang akan dilaksanakan, diantaranya:

Bagan Alir Pelaksanaan

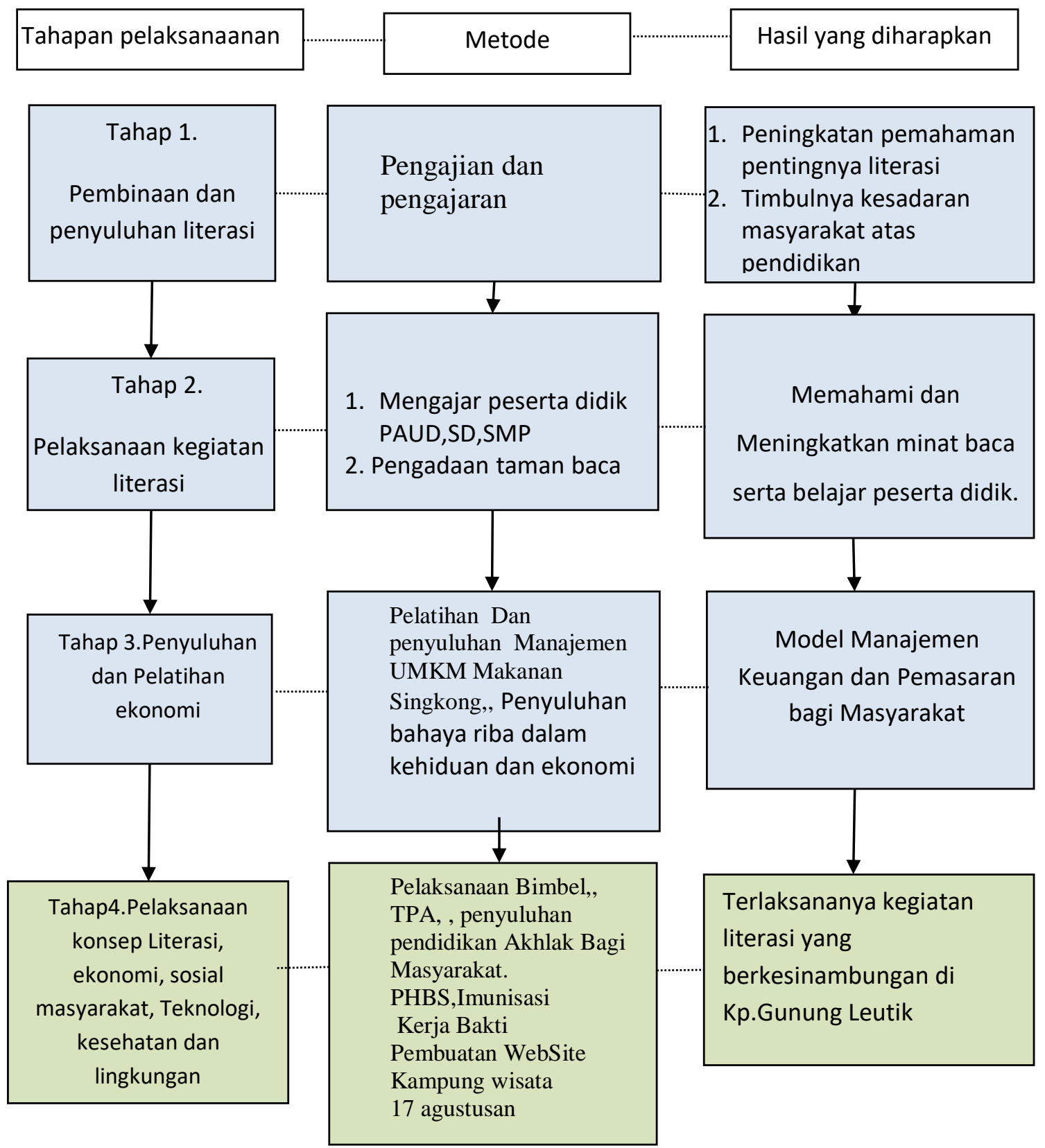

Pendekatan yang digunakan dalam kegiatan ini adalah:

1. Pendekatan religius, yaitu pendekatan yang menggunakan nilai-nilai agama sebagai basis kegiatan.
2. Pendekatan organisasi, yaitu pendekatan dimana sebagian kegiatan diorganisir oleh Masyarakat sekitar posko KKN UIKA kelompok 8 yang berlokasi di kp.gunung leutik, desa benteng, Para Pemuda RW 05, serta SDN gunung 
leutik. Hal ini sesuai dengan hasil penelitian yang dilakukan bahwa keterlibatan organisasi mempunyai pengaruh langsung terhadap toleransi.

3. Pendekatan kekerabatan, artinya bahwa kegiatan yang dilakukan merupakan suatu pembinaan yang dikaitkan dalam rangka membangun kekerabatan antara masyarakat sekitar desa sukaresmi dan hal ini dapat membangun suatu lingkungan kekeluargaan serta mempererat tali silaturahmi.

4. Pendekatan berdasarkan karakter masyarakat, yakni pembinaan yang dilakukan akan disesuaikan dengan karakter masyarakat. Joyce dan Weil (1996) mengungkapkan bahwa model pendidikan yang relevan dengan perilaku sosial dan nilai adalah dengan banyak memberikan permainan peran. Hal ini dilakukan untuk memberi pengalaman riil kepada peserta didik tentang sesuatu yang dilakukan atau dirasakan oleh orang lain. Memang, dalam prakteknya, tidak seluruh aspek harus menggunakan permainan ini. Dalam beberapa hal, terdapat kegiatankegiatan yang hanya golongan tertentu untuk melakukannya. Sejalan dengan konsep Joyce dan Weil, cooperative learning yang digagas Slavin (2005) dapat digunakan untuk membangun kesadaran toleransi masyarakat. Hal ini karena penekanan dari konsep pendidikan ini adalah kerjasama yang merupakan urat nadi toleransi. Dengan demikian, model pendidikan yang akan dibangun menggunakan dua konsep utama yaitu role playing model dan cooperative learning model.
Partisipasi Masyarakat

dalam

\section{Pelaksanaan Program}

Partisipasi masyarakat yang dapat dilakukan dalam kegiatan ini adalah sebagai berikut:

1. Mempersiapkan masyarakat mulai dari orang tua hingga anak anak yang bersedia mengikuti pembinaan program pendidikan non formal dan mempersiapkan tempat untuk pembinaan dan pelatihan.

2. Mempersiapkan tempat untuk pembinaan pendidikan non formal

3. Pelaksana kegiatan pembinaan, terutama tentang pendidikan.

4. Bersama-sama dengan Tim Pengusul melakukan monitoring pelaksanaan pembinaan dan pelatihan.

\section{Langkah Evaluasi}

Evaluasi yang akan dilakukan terdiri dari:

1. Evaluasi proses, yang terkait dengan perencanaan, pelaksanaan dan monitoring kegiatan. Evaluasi proses akan dilakukan setiap pekan bersama dengan masyarakat.

2. Evaluasi hasil, yang akan dilaksanakan setelah kegiatan dilaksanakan. Evaluasi hasil ditujukan untuk menguji pemahaman masyarakat tentang pentingnya pendidikan.

3. Evaluasi dampak, yang akan dilakukan 6 (enam) bulan setelah pelaksanaan pembinaan. Evaluasi dampak diarahkan untuk melihat efektivitas model pembinaan dan keberlangsungan industri rumah tangga (Gall, Gall, dan Borg, 2003). 


\section{REALISASI PROGAM}

Pelaksanaan Program Pelaksanaan Program Harian Mahasiswa dilokasi KKN Universitas Ibn Khaldun Bogor

\section{Bidang Pendidikan}

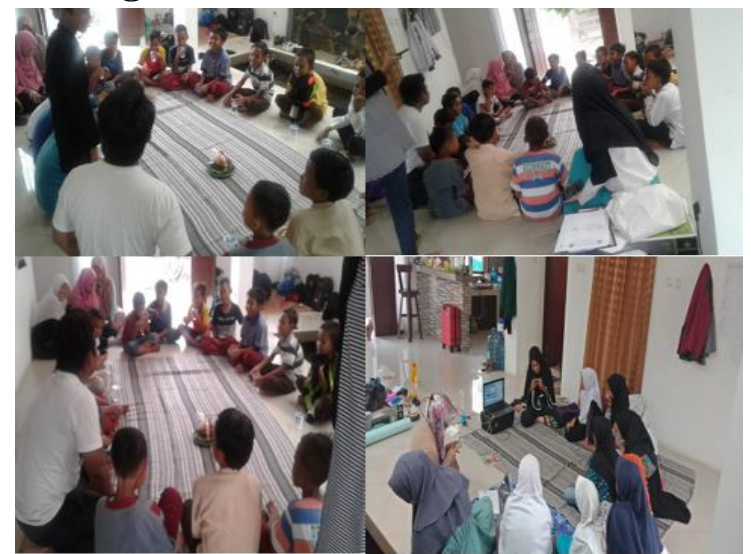

1. Bimbingan Belajar

Adanya antusias anak-anak dalam belajar, serta adanya peningkatan keterampilan anak-anak dalam pelajaran bahasa Inggris,MTK,PAI.

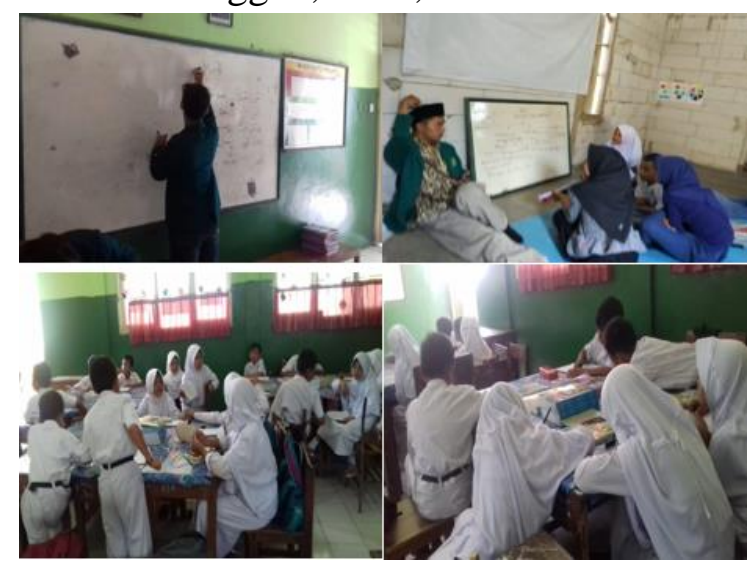

2. Mengajar di PAUD,SD,\&SMP

Adanya Antusias anak anak dalam belajar,serta adanya peningkatan keterampilan mengajar guru guru di sekolah.

\section{Bidang Ekonomi}

a. Penyuluhan bahaya riba dalam kehidupan dan ekonomi

Para masyarakat Rw 05 supaya sadar bahwa betapa bahayanya meminjam uang kepada bank keliling.dan mengkonsumsi Riba.

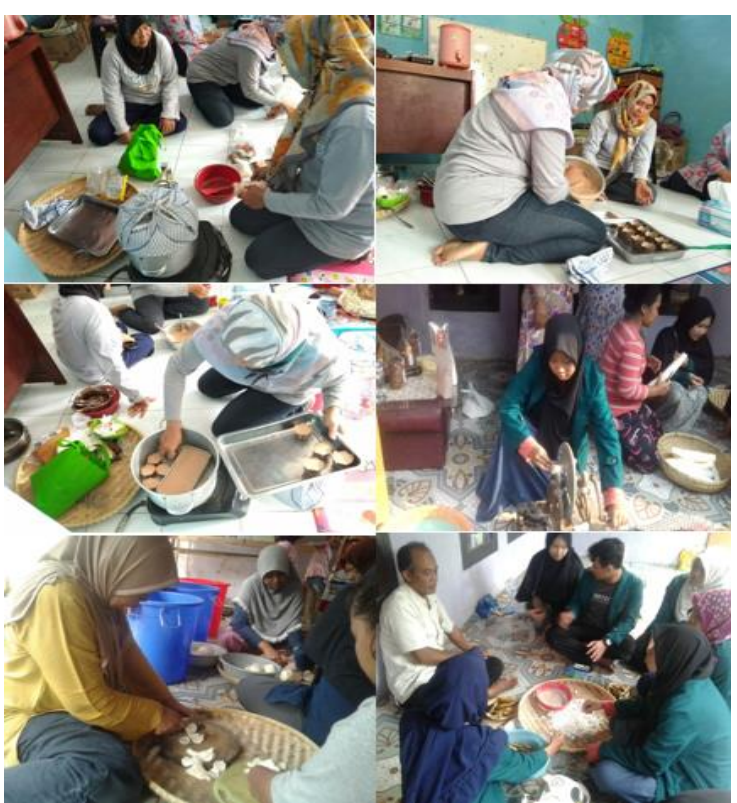

b. Pelatihan Dan Penyuluhan Hasil Tani Warga

Capaian program ini yaitu membuat kue Broncav Dan emping Dan Membuat tepung Mocav. Dengan pelatihan tersebut para ibu memiliki peluang untuk membuat lahan bisnis baru, Pelatihan Ini Bekerja Sama dengan IPB.

\section{Bidang kesehatan Lingkungan}

a. Penyuluhan Kesehatan dan Kerja Bakti

Meningkatnya pemahaman anak anak akan pentingnya hidup sehat dan bersih. Adanya kesadaran masyarakat akan pentingnya kebersihan lingkungan

Bidang Sosial Masyarakat ( Bekerja Sama Dengan Bidang hukum)

Termotivasinya semangat pemuda dalam membangun masyarakat serta sosial Dan membangun akhlak masyarakat yang islami dan berjiwa pemimpin.

\section{Bidang Teknologi}

a. Website Kampung wisata CASAVA,

Dengan adanya kegiatan tersebut maka pelaksanaan kegiatan KKN Mahasiswa Uika Bogor tahun 2018 di Desa Benteng dapat membantu masyarakat dan pemuda untuk menjadikan desa Benteng sebagai desa wisata melalui 
media website Kampung wisata Casava, Hal yang mendukung dengan adanya kegiatan ini adalah sebagai berikut : 1.Adanya Dukungan dari masyarakat. 2. Pemuda, karang taruna.

b. Pengenalan sistem instalasi listrik rumah tangga yang baik dan benar, Dengan Adanya kegiatan tersebut dapat membantu masyarakat kp.gunung leutik,Rw 05 termotivasi cara memakai listrik rumah tangga yang baik dan benar.
Bidang Pengabdian Di Masyarakat

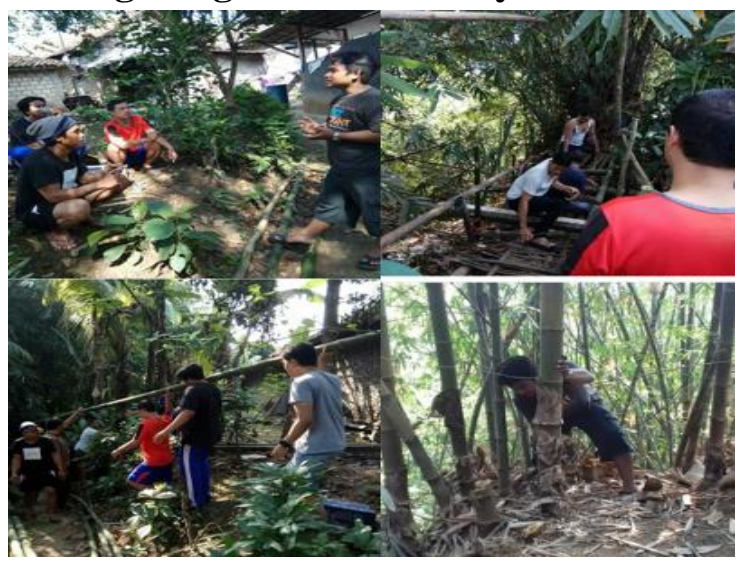

1. Pembuatan Jembatan Penyebrangan ke kali cihideung hilir RT 06/05 Kp.Gunung leutik, Dengan adanya kegiatan tersebut maka pelaksanaan kegiatan KKN Mahasiswa Uika Bogor tahun 2018 di Desa Benteng dapat membantu masyarakat dalam mempermudah akses jalan ke kali cihideung.

2. Dekorasi PAUD Syamil

mahasiswa KKN desa benteng melakukan pelukisan dinding di ruang kelas dengan gotong royong untuk mengebut proses finishing agar berhasilnya program kerja mewarnai ruang kelas, proses pengerjaan ini membutuhkan waktu kurang lebih sekitar 7 hari, dengan agenda:

- membuat sketsa

- mewarnai sketsa

- finishing serta memperindah lukisan 


\section{KESIMPULAN}

Masyarakat desa benteng RW 05 sangat antusias dengan program kegiatan yang dijalankan. Masyarakat desa benteng sangat antusias dengan program kegiatan dalam bidang pendidikan. Masyarakat sangat membantu dalam melaksanakan segala kegiatan sehingga dapat berjalan dengan lancar. Walaupun sedikit terkendala dalam mengajak bapak bapak karena kebanyakan dari mereka sibuk menjadi petani,dan pekerja. Masalah kebersihan menjadi masalah yang harus segera ditanggulangi karena dilingkungan

\section{SARAN}

Berdasarkan kesimpulan yang telah dipaparkan maka penulis mengajukan saran yang dipandang berguna dan yang dapat mempertimbangkan agar dapat meningkatkan kompetensi masyarakat pada bidang pendidikan khususnya dan

\section{REFERENSI}

Gall, M.D., Gall, J.P. dan Borg,W.R. (2003). Educational Research an Introduction. Boston: Pearson Education, Inc.

Joyce, Bruce dan Weil, Marsha. (1996). Models of Teaching. Boston: Allyn and Bacon.

Achmad, Munib.2004.pengantar ilmu pendidikan. Semarang: UPT UNNES PRESS. sekitar Rw 05 belum ada tempat sampah dan TPU sehingga warga ada yang membuang sampah sembarangan dan sampah kiriman dari desa lain sehingga rw 5 yang berada dihilir jadi imbasnya.

Antusiasme yang tinggi dari anakanak dalam mengikuti bimbingan belajar yang menjadi daya tarik masyarakat selama KKN berlangsung. Begitupun dengan antusias para pemuda dalam setiap agenda yang di laksanakan seperti 17 agustus yang Alhamdulillah sukses berjalan lancar.

bidang lainnya seperti bidang ekonomi, kesehatan dan sosial,dan pemerintah desa agar memperhatikan situasi di rw 05 . Terutama Dibidang ekonomi dan pendidikan.

Sudjana, Nana 1994. Pembinaan dan Pengembangan Kurikulum di Sekolah. Bandung: Sinar Baru Algensindo

Ngalim Purwanto. 1986. Psikologi Pendidikan. Bandung: Remaja Karya. 